\title{
What proportion of congenital abnormalities can be prevented?
}

\author{
Andrew E Czeizel, Zsolt Intôdy, Bernadette Modell
}

\begin{abstract}
Objective-To estimate the proportion of preventable congenital abnormalities in Hungary.

Design-Analysis of available Hungarian databases and of the effectiveness of primary, secondary, and tertiary preventive methods.

Setting-Databases of ad hoc epidemiological studies and of the Hungarian congenital abnormality registry.

Main outcome measures-Prevalence at birth and prevalence after prevention in 73 congenital abnormality types or groups.

Results-Preventive methods are available for $51(70 \%)$ of the 73 congenital abnormality types or groups evaluated. The birth prevalence of all congenital abnormalities could be reduced from 65 to 26 per 1000 ; thus 39 per $1000(60 \%)$ are preventable. Without congenital dislocation of the hip, which is unusually common in Hungary, the preventable proportion of congenital abnormalities is $52 \%$.
\end{abstract}

Conclusion-Many congenital abnormalities can be prevented, but as they do not represent a single pathological category there is no single strategy for their prevention.

\section{Introduction}

In countries where the infant mortality is low, a large proportion of residual infant deaths are due to congenital anomalies (defined as "structural-morphological, functional and/or biochemical-molecular defects present at birth").' Further reduction of infant mortality and chronic handicap depends increasingly on prevention of such disorders. The largest group of congenital anomalies are congenital abnormalities (or malformations), defined as structural defects present at birth, whether detected at that time or not. We collected data on the birth prevalence of congenital abnormalities in Hungary, where the Hungarian congenital abnormality registry provides a longstanding information resource.

Congenital abnormalities can be divided into three groups: lethal if the developmental defect causes stillbirth or infant death in more than $50 \%$ of cases; severe if without medical intervention the congenital abnormality causes handicap or death; mild if the congenital abnormality requires medical intervention but life expectancy is good. Lethal and severe defects together constitute major congenital abnormalities. Minor anomalies or morphological variants without serious medical or cosmetic consequences ${ }^{2}$ are excluded from this discussion.

Preventive approaches are often classified as primary (avoiding the abnormality arising in the first place), secondary (early detection and medical treatment, or selective abortion), or tertiary (surgical correction). A congenital abnormality is considered corrected when early paediatric surgery results in there being practically no residual defect, or no or minimal after effects.
We used the Hungarian congenital abnormality registry and other collected data to estimate the proportion of congenital abnormalities that are, or can be, prevented by all these approaches when used to the best level of practice currently found in Hungary.

\section{Methods}

Over the past 20 years the National Institute of Hygiene has collected information on the prevalence at birth of congenital abnormalities in Hungary using three different approaches.

Firstly, in the 1970s and ' 80 s ad hoc epidemiological studies were used for all of the common $(\geqslant 1 / 10000)$ and most of the moderately common congenital abnormalities. All institutions providing paediatric care or paediatric surgery were visited, and the records of all cases in the study period were reviewed. Cases were ascertained and the validity of the diagnoses was checked.

Secondly, since 1970 the Hungarian congenital abnormality registry has kept a record of all stillborn and liveborn infants with a congenital abnormality detected before the age of 1 year in Hungary. ${ }^{3}$ Physicians must report children with congenital abnormalities. The registry has four main sources of information: practically all deliveries take place in hospital, and obstetricians report congenital abnormalities diagnosed at birth; paediatricians report malformed babies seen at inpatient and outpatient paediatric clinics; necropsy is obligatory in case of infant death and when the infant has a congenital abnormality pathologists send the autopsy report to the Hungarian congenital abnormality registry; the five prenatal diagnosis centres report congenital abnormalities in fetuses aborted after prenatal diagnosis of fetal defect-all diagnoses are checked, and abnormalities are classified as either isolated or multiple because of their different aetiologies.

In the 1980 s our work concentrated on multiple congenital abnormalities. ${ }^{4}$ Babies or fetuses with two or more different congenital abnormalities were considered as multimalformed. Complex congenital abnormalities within the same organ (for example, tetralogy of Fallot) or sequences (for example, spina bifida cystica with hydrocephalus and clubfoot, or diaphragmatic defect with lung hypoplasia and dextrocardia) were classified as isolated. Inherited disorders such as cystic fibrosis and functional anomalies such as mental retardation were excluded, but phenylketonuria, galactosaemia, and congenital hypothyroidism were included because they are routinely detected by neonatal screening in Hungary and they may manifest as a congenital abnormality (for example, microcephaly, cataract, umbilical hernia). The unit of evaluation was affected children rather than individual congenital abnormalities.

The birth prevalence of some moderately common and rare congenital abnotwifles not included in the ad hoc epidemiologiçat tot ties was determined from 
the database of the Hungarian congenital abnormality

\begin{tabular}{lccccc}
\hline & \multicolumn{3}{c}{$\begin{array}{c}\text { Birth } \\
\text { ICD code }\end{array}$} & $\begin{array}{c}\text { Total } \\
\text { prevalence }\end{array}$ & Reference \\
pirths & Caser 1000 & SD & No \\
\hline
\end{tabular}
register. Possible underascertainment has been carefully analysed, and a questionnaire was sent to parents, or those affected were invited with their families for a personal examination to check the diagnoses and to obtain necessary data.

Thirdly, for the remainder, the birth prevalence of rare or heterogeneous congenital abnormality groups was based on the Hungarian congenital abnormality registry 1977-81. ${ }^{4}$ We used the averages of the highest three annual birth prevalences to reduce underascertainment.

The proportions of cases in the whole database in the three groups were $78.7 \%, 8.3 \%$, and $13.0 \%$, respectively. These estimates assume no significant "spontaneous" decrease or increase with time and no significant regional differences in the birth prevalence of congenital abnormalities. This is in fact the case for the great majority of congenital abnormalities in Hungary. ${ }^{3}$ The data on which the calculations are based are summarised in table I.

The total prevalence of congenital abnormalities $(\mathrm{N})$ was calculated per 1000 informative pregnancies (n)-that is, live births and stillbirths plus terminations of affected fetuses diagnosed prenatally. In theory, the variability of the prevalence figures could be estimated by calculating the standard deviation either on the basis of observed annual figures within the study period or from a Poisson distribution $[N / n \pm \sqrt{ } N / n] \times 1000$, but we could calculate only from the Poisson distribution because with current preventive practice recent annual prevalence figures were not available.

The severity of congenital abnormalities has been evaluated previously from the Hungarian congenital abnormality registry database 1977-81.5 Estimates of the effectiveness of preventive approaches for 73 congenital abnormality entities were based on data from the registry, epidemiological studies (such as for neural tube defect ${ }^{4}$ and Down's syndrome ${ }^{5}$ ), studies of the effects of, for example, genetic counselling in reducing further conceptions in families at risk, ${ }^{6}$ avoidance of alcohol and other teratogens during pregnancy, ${ }^{7}$ and early paediatric surgery in congenital hypertrophic pyloric stenosis, congenital inguinal hernia, ventricular septal defect, etc.' The approximate effectiveness of preventive methods was calculated using the formula $N^{\star} / n \times 100$, where $N^{\star}$ is the proportion of preventable congenital abnormalities. Prevalence of each congenital abnormality entity after prevention was calculated from the birth prevalence and the percentage effectiveness of prevention. Finally the figures were related to type of preventive approach.

As the standard deviations of the prevalence after prevention (the last column in table II) were derived from different study populations and study periods, we used the following calculation:

$$
\mathbf{n}=\sum_{\mathbf{i}=1}^{\mathbf{m}} \mathbf{n}_{\mathbf{i}} / \mathbf{N}
$$

where $m$ is the number of congenital abnormality entities and $n_{i}$ is the sample size. The corrected sum of the number of cases with congenital abnormalities was calculated as

$$
\mathrm{N}=\sum_{\mathrm{i}=1}^{\mathrm{m}} \frac{\mathrm{N}_{\mathrm{i}}}{\mathbf{n}_{\mathrm{i}}} \mathbf{n}
$$

where $\mathrm{N}_{\mathrm{i}}$ is the number of cases with congenital abnormalities out of $n_{i}$ births.

\section{Results}

In Hungary the birth prevalence of all congenital abnormality entities was about 65 per 1000 births 


\begin{tabular}{|c|c|c|c|c|}
\hline \multirow[b]{2}{*}{ Main approaches } & \multirow[b]{2}{*}{ Congenital abnormalities } & \multicolumn{2}{|c|}{ Prevalence (SD) per 1000 births } & \multirow{2}{*}{$\begin{array}{c}\% \\
\text { Preventable }\end{array}$} \\
\hline & & At birth & After prevention & \\
\hline \multicolumn{5}{|c|}{ Primary prevention } \\
\hline Genetic counselling and reduction of conception & $\begin{array}{l}\text { Familial Mendelian abnormalities such as } \\
\text { anophthalmos or microphthalmos, some congenital } \\
\text { abnormalities of eye and ear, Robin sequence, } \\
\text { monogenic syndromes }(1 / 4)\end{array}$ & $0.91(0.027)$ & $0.83(0.026)$ & 9 \\
\hline $\begin{array}{l}\text { Pre- and postconceptional care of affected (diabetic, } \\
\text { etc) mothers }\end{array}$ & Other teratogenic syndromes $(1 / 10)$ & $0.03(0.005)$ & $0.01(0.003)$ & 67 \\
\hline $\begin{array}{l}\text { Avoidance of teratogens (mainly rubella virus and } \\
\text { alcohol }^{\star} \text { ) during pregnancy }\end{array}$ & & $0.97(0.031)$ & $0.28(0.017)$ & 71 \\
\hline Total & & $1.91(0.041)$ & $1 \cdot 12(0.031)$ & 41 \\
\hline \multicolumn{5}{|c|}{ Secondary prevention } \\
\hline $\begin{array}{l}\text { Prenatal chromosomal exam by CVS or } \\
\text { amniocentesis in mothers over } 35 \text { and maternal } \\
\text { AFP, HCG, oestriol screening }\end{array}$ & $\begin{array}{l}\text { Down's syndrome } \\
\text { Patau's syndrome } \\
\text { Edward's syndrome }\end{array}$ & $1.41(0.037)$ & $0.89(0.030)$ & 37 \\
\hline $\begin{array}{l}\text { Prenatal chromosomal exam by CVS or } \\
\text { amniocentesis in parents with balanced structural } \\
\text { aberrations }\end{array}$ & Other chromosomal syndromes $(1 / 10)$ & $0.03(0.005)$ & $0.02(0.004)$ & 33 \\
\hline Maternal AFP screening and ultrasonography & $\begin{array}{l}\text { Neural tube defect } \\
\text { Congenital abnormalities of abdominal wall } \\
\text { Schisis association }\end{array}$ & $3.08(0.091)$ & $0.55(0.038)$ & 82 \\
\hline Ultrasonography & $\begin{array}{l}\text { Lethal congenital abnormalities: holoprosencephaly, } \\
\text { congenital hydrocephaly, hydrops fetalis, common } \\
\text { truncus, hypoplastic left heart, complex } \\
\text { cardiovascular abnormalities, bilateral renal } \\
\text { agenesis, cystic kidney, abnormalities of } \\
\text { diaphragm } \\
\text { Some severe congenital abnormalities: microcephaly, } \\
\text { other abnormalities of nervous system, oesophageal } \\
\text { atresia, obstructive abnormalities of urinary } \\
\text { system, severe abnormalities of respiratory and } \\
\text { skeletal system, very severe limb reduction } \\
\text { deficiencies, other associations, multiple } \\
\text { abnormalities }\end{array}$ & $7 \cdot 40(0 \cdot 111)$ & $5.02(0.091)$ & 32 \\
\hline Neonatal screening & $\begin{array}{l}\text { Phenylketonuria } \\
\text { Galactosaemia } \\
\text { Congenital hypothyroidism }\end{array}$ & $0.37(0.016)$ & 0 & 100 \\
\hline Neonatal orthopaedic screening of deformations & $\begin{array}{l}\text { Congenital dislocation of hip } \\
\text { Torticollis } \\
\text { Varus, valgus } \\
\text { Other deformities }\end{array}$ & $18 \cdot 34(0 \cdot 200)$ & $2.90(0.080)$ & 84 \\
\hline Specific postnatal treatment & $\begin{array}{l}\text { Patent ductus arteriosus }(1 / 3) \\
\text { Undescended testis }\end{array}$ & $3.94(0.340)$ & $2 \cdot 48(0 \cdot 270)$ & 38 \\
\hline Total & & $34.57(0.232)$ & $11.86(0 \cdot 136)$ & 66 \\
\hline Early paediatric surgery & $\begin{array}{l}\text { Ventricular septal defect } \\
\text { Atrial septal defect type II } \\
\text { Patent ductus arteriosus ( } 2 / 3) \\
\text { Congenital hypertrophic pyloric stenosis } \\
\text { Congenital inguinal hernia }\end{array}$ & & & \\
\hline Total & & $16.02(0.549)$ & $0.33(0.080)$ & 98 \\
\hline Total & & $52.49(0 \cdot 275)$ & $13 \cdot 31(0 \cdot 138)$ & 75 \\
\hline $\begin{array}{l}\text { Abnormalities not preventable (for example, cleft } \\
\text { palate, hypospadias) }\end{array}$ & & $12 \cdot 83(0 \cdot 167)$ & $12 \cdot 84(0 \cdot 167)$ & \\
\hline Grand total & & $65 \cdot 32(0 \cdot 330)$ & $26 \cdot 15(0 \cdot 209)$ & 60 \\
\hline Excluding congenital dislocation of hip & & $51 \cdot 71(0 \cdot 292)$ & $25.06(0.203)$ & 52 \\
\hline
\end{tabular}

*Birth prevalence of congenital rubella syndrome $=0.20 / 1000$; fetal alcohol syndrome $0.70 / 1000$ in Hungary

$\mathrm{CVS}=$ chorionic villus sampling, $\mathrm{AFP}=\alpha$ fetoprotein, $\mathrm{HCG}=$ human chorionic gonadotrophin

TABLE III-Proportions of preventable congenital abnormalities in lethal, severe, and mild groups

\begin{tabular}{lcccc}
\hline & $\begin{array}{c}\text { Prevalence (SD) } \\
\text { per } \\
1000 \text { births }\end{array}$ & $\begin{array}{c}\% \text { Of } \\
\text { congenital abnormalities }\end{array}$ & $\begin{array}{c}\text { Prevalence } \\
\text { after prevention } \\
\text { per } 1000\end{array}$ & $\begin{array}{c}\% \text { Of } \\
\text { preventable } \\
\text { congenital abnormalities }\end{array}$ \\
\hline Lethal & $6 \cdot 15(0 \cdot 10)$ & 9 & $2 \cdot 38(0 \cdot 07)$ & 61 \\
Severe & $19 \cdot 30(0 \cdot 17)$ & 30 & $13 \cdot 98(0 \cdot 14)$ & 28 \\
Mild & $39 \cdot 87(0 \cdot 31)$ & 61 & $9 \cdot 78(0 \cdot 15)$ & 75 \\
\hline Total & $65.32(0.33)$ & 100 & $26 \cdot 15(0 \cdot 21)$ & 60 \\
\hline
\end{tabular}

(table I). All figures corresponded closely to well established figures for Europe and North America, ${ }^{8}$ except for potential congenital dislocation of the hip, which is unusually common in Hungary and probably in other central and eastern European countries. ${ }^{1}$ The birth prevalence of congenital dislocation of the hip was about $1 / 1000$ in western Europe and North America, but a significant (threefold to ninefold) increase was recorded after early orthopaedic screening was introduced.

Table II summarises possible preventive methods. Some preventive methods overlap but only one was considered for each congenital abnormality entity. We included genetic counselling alone, for familial cases when no prenatal diagnosis is available, among primary preventive approaches. Seven groups of secondary preventive approaches are listed. These include treatable congenital abnormalities (such as anal atresia) that may be diagnosed prenatally but for which termination of pregnancy is not indicated because effective treatment is available. Prenatal diagnosis often improves the management of such cases by allowing the baby to be delivered at the best time and place for appropriate surgery. We treated orthopaedic screening as a distinct category because some neonatal deformations (such as congenital dislocation of the hip) represent only a predisposition to congenital abnormality, and surgery is avoided by conservative treatment. We classified specific medical treatments that mimic physiological processes (human chorionic gonadotrophin for undescended testis and indomethacin for patent ductus arteriosus) as secondary prevention. Tertiary prevention consists of paediatric surgery. Only congenital abnormalities in which there are no after effects or these are minimal and there is no need for further medical care after surgery are included.

Table II shows that preventive methods are available for $51(70 \%)$ of 73 congenital abnormality entities evaluated, and their effective application could 


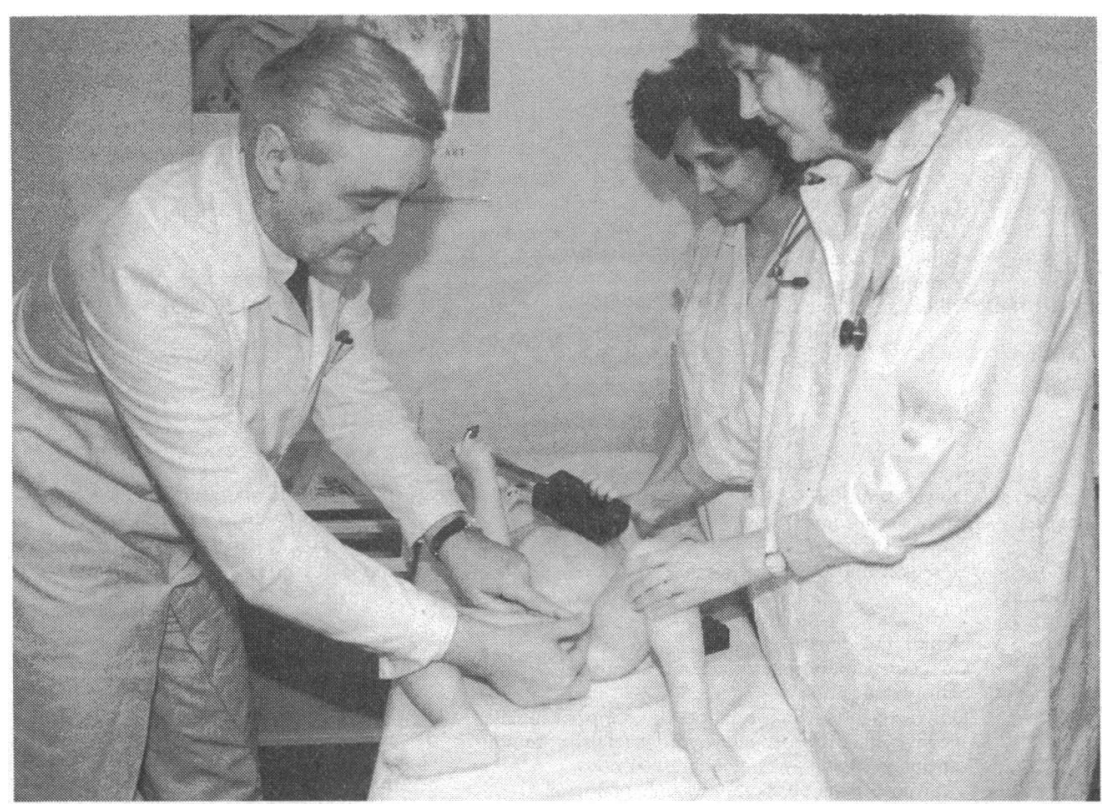

Checking for residual defects in the authors' clinic in Budapest

theoretically reduce the birth prevalence of all congenital abnormalities by $60 \%$ (from $65 / 1000$ to $26 / 1000$ ). When congenital dislocation of the hip is excluded the figure is $52 \%$ (from $52 / 1000$ to $25 / 1000$ ). Primary and secondary prevention could in principle reduce the birth prevalence of congenital abnormalities by about $36 \%$, from $65 / 1000$ to $42 / 1000$, the greater part of the effect being due to secondary prevention. So called tertiary prevention-paediatric surgery-can provide an almost $100 \%$ effective solution in at least another $25 \%$ of cases.

Table III shows the birth prevalence, proportions, and proportion preventable of lethal, severe, and mild congenital abnormalities. About $39 \%$ of the total25/1000 births-are major congenital abnormalities. Preventive methods are most effective for mild, and least effective for severe, congenital abnormalities.

\section{Discussion}

As far as we know, this is the first detailed attempt to estimate the proportion of congenital abnormalities that are preventable. A realistic analysis of current Hungarian data shows that preventive methods are currently available for $70 \%$ of congenital abnormality (malformation) entities, and $60 \%$ of these developmental defects are preventable. With the exception of congenital dislocation of the hip, the Hungarian birth prevalences for congenital abnormalities resemble those of other areas where there is careful recording. ${ }^{10}$ Hungarian figures excluding congenital dislocation of the hip $(51 \cdot 7 / 1000$, of which $52 \%$ might be prevented) may be more appropriate for comparison with western Europe and North America. Future estimates will probably prove more reliable and have more predictive value.

The analysis includes two sets of population based data. Birth prevalences without prevention are real figures observed in ad hoc epidemiological surveys or in the database of the Hungarian congenital abnormality registry, as are birth prevalences after prevention involving selective abortion or neonatal screening. On the other hand, the proportions of congenital abnormalities preventable by secondary and tertiary methods are estimates based on research studies of particular conditions (for example, ad hoc epidemiological studies for measuring the effectiveness of neonatal orthopaedic screening), or regions (for example, those having excellent ultrasound scanning and trained staff for diagnosing structural defects, or using the triple test for detection of Down's syndrome) or of expert groups (for example, specific postnatal treatment and early paediatric surgery). The estimates for the effect of primary preventive approaches are theoretical calculations based on our previous papers. ${ }^{89}$

\section{PREVENTIVE APPROACHES}

The contribution of primary prevention is small and limited mainly to avoiding single gene defects, teratogens (by rubella vaccination, for example) and teratogenic effects of maternal disorders. Heterozygote screening and DNA probes will permit more effective prevention of genetic disorders in the future, and periconceptional multivitamin or folate supplementation will be advantageous in primary prevention of neural tube defects. ${ }^{10-12}$

Among methods for secondary prevention, prenatal screening, especially ultrasonography, is particularly effective, though obviously abortion of a seriously malformed fetus is a last resort rather than an optimal solution. Informed parents have to choose the lesser of two evils, and usually choose to prevent the birth of the affected fetus, but the decision can sometimes be very difficult. There may be uncertainties in interpreting an ultrasound picture; the prognosis of the abnormality detected is not always known; and in some groups of defects, such as oesophageal atresia or obstructive defects of urinary system, it is not always clear whether the defect is so severe as to justify abortion or whether surgery might be successful. It is often said that most congenital abnormalities are untreatable, but this overlooks the great contribution of tertiary prevention, and surgical techniques are constantly improving.

The figures in this report are based on the best current Hungarian practice. Recent reports suggesting that $70-80 \%$ of severe congenital abnormalities may be detected by routine fetal anomaly scanning by trained non-medical operators with modern equipment ${ }^{13}$ would considerably increase the proportion of preventable congenital abnormalities. It is also possible to increase the effectiveness of other forms of prenatal screening. For example, it is estimated that about $60 \%$ of Down's syndrome and other trisomic syndromes can be detected using the triple test (maternal serum $\alpha$ fetoprotein, unconjugated oestriol, and human chorionic gonadotrophin, combined with maternal age). ${ }^{14}$ 15 Though neonatal screening for hypothyroidism, phenylketonuria, and galactosaemia is very effective, its contribution is limited. Neonatal orthopaedic screening is particularly important in Hungary, where congenital dislocation of the hip is the commonest congenital abnormality.

As many congenital abnormalities can be prevented, these developmental defects should not be considered an irreducible component of perinatal mortality. However, as they vary so greatly in cause and course there is no single strategy for prevention. The efficacy of prevention could be improved considerably by promoting widespread use of the approaches that are now available, but this will require further support from public health authorities for periconceptional care and screening programmes. The Hungarian example shows that each country represents a special situation with its specific problems, pattern of congenital abnormalities, resources, and needs.

The authors will supply, on request, the database of birth prevalences of different congenital abnormality entities and their references; the database of 73 congenital abnormality entities that was the basis of this calculation; and the data of congenital abnormality entities within different preventive approaches.

1 Czeizel A, Tusnády G. Aetiological studies of isolated common congenital abnormalities in Hungary. Budapest: Akadémiai Könyvkiadó, 1984.

2 Méhes K. Minor malformations in neonates. Budapest: Akadémiai Könyvkiadó, 983.

Czeizel A. The activities of the Hungarian Centre for Congenital Anomaly Control. World Health Stat Q 1988;41:219-27. 
4 Kalmár $\mathrm{Zs}$, Czeizel A. The analysis of preventive programme of neural tube defects. Orvosi Hetilap 1980;:1205-12. (In Hungarian.)

5 Béres J, Czeizel A. The frequency of prenatal chromosome analysis in pregnan women over 40 in Hungary. Orvosi Hetilap 1988;129:529. (In Hungarian.)

6 Czeizel A, Métneki J, Osztovics M. Evaluation of information-guidance genetic counselling. F Med Genet 1981;18:91-8.

7 Czeizel A, Métneki J. Evaluation of counselling for pregnant women exposed to potentially hazardous environmental factors. Acta Paediat Hung 1985;26:175-86.

8 Congenital malformations worldwide: a repon from the International Clearinghouse for Birth Defects Monitoring Systems. Amsterdam: Elsevier, 1991.

9 Woolf CM, Koehn JH, Coleman SS. Congenital hip disease in Utah: the influence of genetic and nongenetic factor. Am f Hum Genet 1968;20:430-9.

10 Smithells RW, Sheppard S, Wild J, Schorah CJ. Prevention of neural tube defect recurrences in Yorkshire: final report. Lancet 1989;ii:498-9.
11 MRC Vitamin Study Research Group. Prevention of neural tube defects: result of the MRC vitamin study. Lancet 1991;338:131-7.

12 Czeizel A. Prevention of the first occurrence of neural tube defect. Results of the Hungarian randomised controlled trial of periconceptional multivitamin supplementation. N Engl $\mathcal{F}$ Med 1992;327:1832-5.

13 Luck CA. Value of routine ultrasound scanning at 19 weeks: a four year study of 8849 deliveries. $B M$ I $^{1992 ; 304: 1474-6 .}$

14 Sheldon TA, Simpson J. Appraisal of a new scheme for prenatal screening fo Down's syndrome. BMF 1991;302:1133-6.

15 Wald NJ, Kennard A, Densem JW, Cuckle HS, Chard T, Butler L. Antenata maternal serum screening for Down's syndrome: results of a demonstration project. $B M \Im$ 1992;305:391-4.

(Accepted 30 October 1992)

\title{
Health care in Brazil
}

\author{
Andy Haines
}

Brazil has great geopolitical importance because of its size, environmental resources, and potential economic power. The organisation of its health care system reflects the schisms within Brazilian society. High technology private care is available to the rich and inadequate public care to the poor. Limited financial resources have been overconcentrated on health care in the hospital sector and health professionals are generally inappropriately trained to meet the needs of the community. However, recent changes in the organisation of health care are taking power away from federal government to state and local authorities. This should help the process of reform, but many vested interests remain to be overcome. A link programme between Britain and Brazil focusing on primary care has resulted in exchange of ideas and staff between the two countries. If primary care in Brazil can be improved it could help to narrow the health divide between rich and poor.

Brazil has often been in the news because of the impeachment of President Collor, the Rio conference, widespread concern about environmental issues ${ }^{1}$ and violence, including the murder of street children, and, most recently, prisoners in Sao Paulo. ${ }^{2}$ Much less has been written about the organisation of health care in the country. Brazil is a country of contrasts. These are exemplified in the health sector by gleaming tertiary care and research institutes in major cities such as Sao Paulo and poorly equipped or absent health posts in the

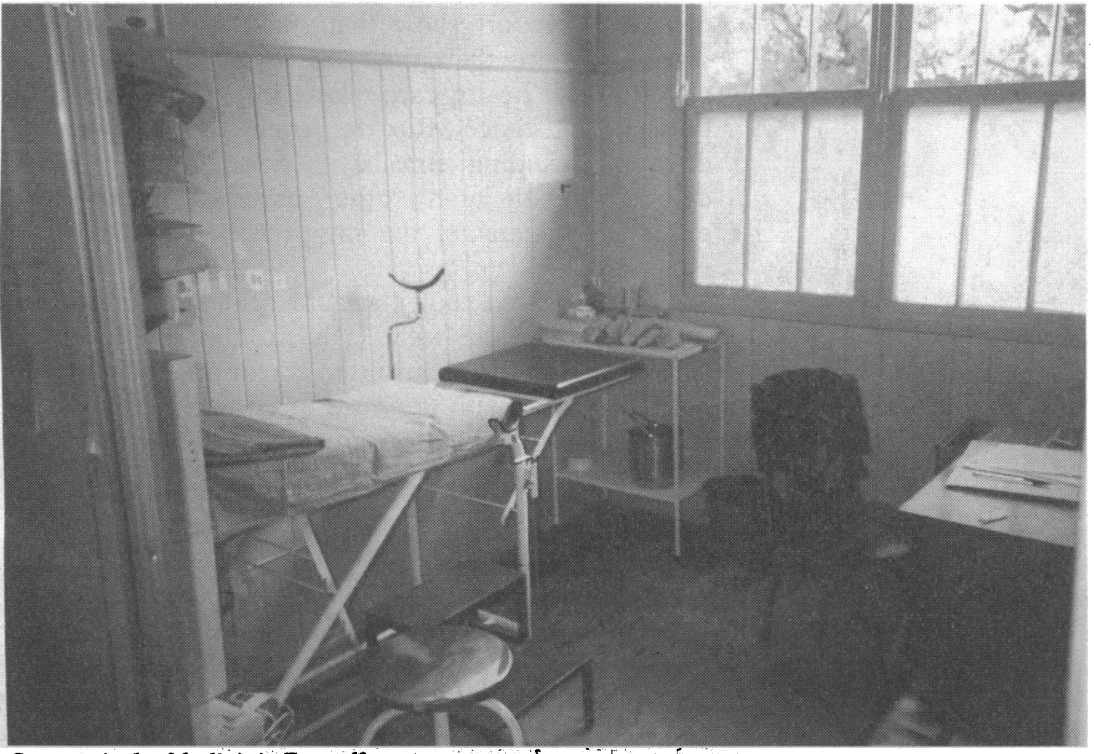

ubiquitous shanty towns (favelas). Brazil has a heavy burden of international debt, which is a major contributor to its economic and health problems, ${ }^{3}$ but wealth is also characterised by striking internal divisions. The top $20 \%$ of the population have 26 times the income of the bottom $20 \%$, one of the largest differentials in the world. ${ }^{4}$ The statistics given in the table illustrate some of the schisms in Brazilian society.

Comparison of health and wealth in Brazil with other countries with medium human development

\begin{tabular}{|c|c|c|c|}
\hline$\cdot$ & Year & Brazil & $\begin{array}{l}\text { Average for } \\
\text { medium }{ }^{\star} \text { human } \\
\text { development } \\
\text { countries }\end{array}$ \\
\hline Infant mortality (per 1000 live births) & 1990 & 60 & 40 \\
\hline $\begin{array}{l}\text { Under } 5 \text { mortality (per } 1000 \text { live } \\
\text { births) }\end{array}$ & & & 55 \\
\hline$\%$ Of children immunised at 1 year & $1988-90$ & 83 & 89 \\
\hline$\%$ Of mothers breast feeding at 1 year & $1980-90$ & 34 & 45 \\
\hline $\begin{array}{l}\% \text { Of children under } 5 \text { underweight } \\
\text { Maternal mortality (per } 100000 \text { live }\end{array}$ & $1980-90$ & 7 & 20 \\
\hline births) & 1988 & 230 & 170 \\
\hline Population per doctor & 1984 & 1080 & 1500 \\
\hline Population per nurse & 1984 & 1210 & 1540 \\
\hline Public expenditure on health $(\%$ of & & & \\
\hline GNP) & 1987 & 1.7 & 1.5 \\
\hline $\begin{array}{l}\% \text { Completing primary education } \\
\text { Tertiary education enrolment }\end{array}$ & 1988 & 20 & 74 \\
\hline $\begin{array}{l}\text { Tertiary education enrolment } \\
\text { rate }(\%) \\
\text { Public expenditure on education }\end{array}$ & $1988-9$ & 11 & 6 \\
\hline $\begin{array}{l}(\% \text { GNP) } \\
\text { Televisions per } 1000 \text { people } \\
\text { GNP per capita (US\$) }\end{array}$ & $\begin{array}{l}1989 \\
1988-9 \\
1989\end{array}$ & $\begin{array}{l}3 \cdot 7 \\
204 \\
2500\end{array}$ & $\begin{array}{l}3 \cdot 8 \\
64 \\
924\end{array}$ \\
\hline
\end{tabular}

GNP = gross national product.

*Defined as a country which has a human development index (HDI) of $0 \cdot 500-0 \cdot 799$. The index is a measure of development devised by the UN Development Programme. It includes three key components: longevity, knowledge (audit literacy and mean years of schooling), and income. These are combined in a three step process to form an average deprivation index with a maximum value of 1.0 .

The death rates in infants and children under 5 are higher than in countries of equivalent development. The number of televisions per 1000 people is three times higher. Although the ratio of doctors to nurses is high most of the population have poor medical facilities.

\section{Organisation of health care}

Until 1987, there were entrenched divisions in the organisation of health care. Curative treatment and medical care were the responsibility of the social security ministry agency Instituto Nacional de Assistencia Medica Previdencia Social. Care was provided by units run by the agency and accredited private services. Preventive activities and communicable diseases were the responsibility of the health minister and state health secretariats, which ran health centres, public health laboratories, and hospitals specialising in transmissible diseases. In 1988 Brazil 